Article

\title{
Are Shell Strength Phenotypic Traits in Mussels Associated with Species Alone?
}

\author{
Stefano Carboni ${ }^{1, *(\mathbb{D})}$, Sarah Evans ${ }^{1,2},{\text { K. Elizabeth } \text { Tanner }^{3}(\mathbb{D}) \text {, Andrew Davie }}^{1} \mathbb{D}$ and Michaël Bekaert ${ }^{1}(\mathbb{D})$ \\ and Susan C. Fitzer ${ }^{1}$ (D)
}

1 Institute of Aquaculture, School of Natural Sciences, University of Stirling, Stirling FK9 4LA, UK; sarahe@scottishshellfish.co.uk (S.E.); andrew.davie@stir.ac.uk (A.D.); michael.bekaert@stir.ac.uk (M.B.); susan.fitzer@stir.ac.uk (S.C.F.)

2 Scottish Shellfish Marketing Group, Bellshill, Glasgow ML4 3NZ, UK

3 School of Engineering and Materials Science, Queen Mary University of London, London E1 4NS, UK; k.e.tanner@qmul.ac.uk

* Correspondence: stefano.carboni@stir.ac.uk; Tel.: +44-(0)-1786-467912

check for updates

Citation: Carboni, S.; Evans, S.; Tanner, K.E.; Davie, A.; Bekaert, M.; Fitzer, S.C. Are Shell Strength Phenotypic Traits in Mussels Associated with Species Alone? Aquac. J. 2021, 1, 3-13. https:// doi.org/10.3390/aquacj1010002

Academic Editor: Kenji Saitoh

Received: 7 June 2021

Accepted: 16 July 2021

Published: 23 July 2021

Publisher's Note: MDPI stays neutral with regard to jurisdictional claims in published maps and institutional affiliations.

Copyright: (c) 2021 by the authors. Licensee MDPI, Basel, Switzerland. This article is an open access article distributed under the terms and conditions of the Creative Commons Attribution (CC BY) license (https:/ / creativecommons.org/licenses/by/ $4.0 /)$.

\begin{abstract}
Mussels often hybridise to form the Mytilus species complex comprised of M. edulis and M. galloprovincialis as the main species cultivated in Europe and, where their geographical distribution overlaps, the species $M$. trossulus. It has been suggested that $M$. trossulus have a weaker shell than the UK native M. edulis and hybridisation reduces farmed mussel yields and overall fitness. Here, we investigate the hypothesised link between species and shell weakness, employing multi-locus genotyping combined with measurements of six different phenotypes indicative of shell strength (shell thickness, flexural strength, Young's modulus, Vicker's hardness, fracture toughness, calcite and aragonite crystallographic orientation). Historic evidence from shell strength studies assumed species designation based on geographical origin, single locus DNA marker or allozyme genetic techniques that are limited in their ability to discern hybrid individuals. Single nucleotide polymorphic markers have now been developed with the ability to better distinguish between the species of the complex and their hybrids. Our study indicates that shell strength phenotypic traits are less associated with species than previously thought. The application of techniques outlined in this study challenges the historic influence of $M$. trossulus hybridisation on mussel yields and opens up potential for the environment to determine mussel shell fitness.
\end{abstract}

Keywords: Mytilus species complex; biominerals; material properties; micro-indentation; aquaculture

\section{Introduction}

Mussels Mytilus edulis and Mytilus galloprovincialis are the common species cultivated in Europe and both freely hybridise with Mytilus trossulus wherever their geographical distribution overlaps [1,2], forming the European Mytilus Species Complex [3]. Various degrees of hybridisation of the common blue mussel, M. edulis with $M$. trossulus, have been reported to produce mussels with weaker shells $[4,5]$ more vulnerable to damage by predation and prone to fracture during commercial harvesting. Mussel productivity is reportedly limited by the occurrence of $M$. trossulus and its hybrids in certain areas [6,7]. M. trossulus has been listed as a commercially damaging species under the Aquaculture and Fisheries (Scotland) Act 2013 [8]. Current legislation has been informed by previous reports which correlate weaker shells and the genotype of tested individuals using single-locus DNA markers. The single locus DNA marker Me15/16 is the most commonly applied sequence in the gene that encodes for the polyphenolic foot protein, sometimes in combination with allozymes, to identify species within the European Mytilus complex across the world including Scotland [5,9], Ireland [10] and Chile [11]. The number of individuals identified as 'pure' can be overestimated using this approach [3], therefore association between weaker shells and genotype remain dubious [6]. To establish a link between 
genotype and shell strength, it is important to employ suitable methods to unequivocally assign individuals to species or hybrids and to assess shell material properties without confounding factors (e.g., shell geometry). Shell strength tests employed so far have been conducted using crush tests on whole shells, for example, using an electric force gauge applied at the widest part of the shell, omitting the impact of the heterogeneous shell shape and geometry on the results [12]. The standardisation of whole shell crushing tests and comparisons between individuals with heterogeneous shell shapes are therefore unreliable. Historic theories, that hybridisation with $M$. trossulus result in a weaker shell, is also limited by the use of single locus genotyping, combined with the difficulties in the standardisation of the methods used to determine shell strength.

Here, we challenge the hypothesised link between species and shell weakness, we employ multilocus genotyping combined with the measurements of six different phenotypes indicative of shell strength (shell thickness, flexural strength, Young's modulus, Vicker's hardness, fracture toughness, calcite and aragonite crystallographic orientation). We target commercially grown mussels grown in a sympatric population exhibiting the same environmental conditions to rule out the influence of environment. This is the first study to combine micro-indentation, three-point bending and crystallographic orientation to evaluate the material properties of the shell in combination with a nine diagnostic Single Nucleotide Polymorphic (SNP) marker genotyping [3] to establish the link more robustly between shell phenotypes and mussel genotype.

\section{Materials and Methods}

\subsection{Sample Sourcing}

Mussels belonging to the same cohort (60 mussels, 3 years of age) were collected from a commercial farm in Loch Fyne (Argyll, Scotland, UK) and transported to the laboratory where shells were gently cleaned by hand scraping (shell length, $66.75 \pm 7.04 \mathrm{~g}$ and wet weight, $26.6 \pm 5.82 \mathrm{~g}$ ). Mussels were dissected, the foot removed and stored in $95 \%$ ethanol at $4{ }^{\circ} \mathrm{C}$ awaiting DNA extraction. The cleaned empty shells were kept in cold storage at $4{ }^{\circ} \mathrm{C}$ until dry and were subsequently prepared for material properties testing. The temperature and salinity profiles of the first $10 \mathrm{~m}$ in depth (relevant for mussel farming) for the study location have been gathered as secondary data from the Scottish Environment Protection Agency (SEPA) database.

\subsection{DNA Extraction and Quantification}

Mussel foot tissue was digested overnight at $60{ }^{\circ} \mathrm{C}$ in a lysis buffer $(200 \mu \mathrm{L}$ SSTNE buffer, $20 \mu \mathrm{L} 10 \%$ SDS, $5 \mu \mathrm{L}$ Proteinase $\mathrm{K}(10 \mathrm{mg} / \mathrm{mL})$ and $5 \mu \mathrm{L}$ RNase A $(2 \mathrm{mg} / \mathrm{mL})$. Proteins were precipitated down, removed and the DNA was precipitated in isopropanol which was spun down to form a pellet. The pellet was washed twice in ethanol, which was then evaporated, and the DNA re-suspended in $20 \mu \mathrm{L}, 5 \mathrm{mM}$ Tris ( $\mathrm{pH}$ 8.0). The DNA yield was quantified on the nanodrop (ND 1000, Thermo Fisher Scientific) using $5 \mathrm{mM}$ Tris as a blank. Each sample was diluted down to $50 \mathrm{ng} / \mathrm{mL}$ using $5 \mathrm{mM}$ Tris as a buffer. The DNA was run on agarose gel using a Lambda Hind III ladder as a quality control step.

\subsection{Kompetitive Allele Specific PCR (KASP) Assay}

KASP assays were performed according to Wilson et al. [3]. Each $5 \mu \mathrm{L}$ reaction consisted of $2.5 \mu \mathrm{L}$ KASP master mix (containing Taq polymerase, free nucleotides, $\mathrm{MgCl}_{2}$ and FRET cassettes; one with the SYBR dye and one with the HEX ${ }^{\mathrm{TM}}$ dye), $0.07 \mu \mathrm{L}$ KASP assay mix (containing two allele specific forward primers and one reverse primer), $1.43 \mu \mathrm{L}$ milli-Q ${ }^{\circledR}$ water and $1 \mu \mathrm{L}$ DNA sample as per the manufacturer's guidelines. As well as the DNA samples collected in this study, DNA from known pure homozygous populations was included in the PCR analysis, three samples for each species (M. edulis, M. trossulus and M. galloprovincialis) as reference populations. Reference M. edulis samples came from Rascarrel Bay in Scotland, M. trossulus from Penn Cove in North America and M. galloprovincialis from the Bay of Piran in Slovenia. In total, nine plates were run with different SNP as- 
says, three were homozygous for M. edulis (E1, E2 and E3), three were homozygous for M. trossulus (T1, T2 and T3) and three were homozygous for M. galloprovincialis (G1, G2 and G3). The diagnostic ability of all markers used here has been verified in previous work [3]. All plates were run on a Biometra TAdvanced thermocycler under standard KASP conditions: $94{ }^{\circ} \mathrm{C}$ or $15 \mathrm{~min}$; [ $94{ }^{\circ} \mathrm{C}$ for $20 \mathrm{~s}$ followed by $61-55^{\circ} \mathrm{C}$ for $120 \mathrm{~s}\left(0.6{ }^{\circ} \mathrm{C}\right.$ drop per cycle) $] \times 10$; and $\left[94^{\circ} \mathrm{C}\right.$ for $20 \mathrm{~s}$ and $55^{\circ} \mathrm{C}$ for $\left.120 \mathrm{~s}\right] \times 40$. Following PCR, the fluorescent signals were detected on a Techne Quantica real time PCR thermocycler, using Quansoft software to record each genotypic assay based on the relative fluorescence levels of the SYBR and HEX ${ }^{\mathrm{TM}}$ dyes. Homozygous for all three 'M. edulis' alleles were considered pure $M$. edulis, homozygous for all three 'M. trossulus' alleles were considered pure M. trossulus, homozygous for all three 'M. galloprovincialis' alleles were considered pure M. galloprovincialis and heterozygous for all six 'M. edulis/M. trossulus', or 'M. edulis/M. galloprovincialis', or 'M. trossulus/M. galloprovincialis' alleles were considered F1 hybrids. The returned genotype for each individual was then used to identify corresponding shells for the assessment of shell physical properties, discarding all individuals presenting ancestries more complex than F1 hybrids to avoid confounding factors.

\subsection{Micro-Indentation}

Shells belonging to M. edulis, M. trossulus and F1 hybrids individuals (Table 1), were used for fracture toughness analysis using Vicker's hardness micro-indentation (Wilson ${ }^{\circledR}$ Vickers 401 MVA micro-indentation hardness tester) method [13]. Shells were embedded in resin, sliced transversely, and polished through to $0.06 \mathrm{~mm}$ colloidal silica. Resin blocks were polished by hand for 2-4 min using grit papers (P320, P800, P1200, P2500, and P4000), followed by further polishing for $4 \mathrm{~min}$ on cloths using $1 \mu \mathrm{m}$ and $0.3 \mu \mathrm{m}$ alpha alumina, and 8 min using colloidal silica to produce a smooth cross-sectional shell surface [13]. A total of 10 pyramid shaped indents were made in the calcite region of each shell using a $0.5 \mathrm{~kg}$ force applied for $10 \mathrm{~s}$. The lengths of the diagonals of each indent were measured to calculate Vicker's hardness $(H)$ and the length of the cracks coming outwards from the corners of the indent $(c)$ were measured to calculate fracture toughness $\left(\mathrm{K}_{I C}\right)$ using the following equation, where $a$ is half the average length of the diagonals of the indent $[13,14]$ :

$$
\mathrm{K}_{I C}=0.16\left(\frac{c}{a}\right)^{-1.5} \cdot \sqrt{H(a)}
$$

Table 1. Detailed genotypes for each individual mussel sample from the KASP assays and the performed assessment of the phenotypes (see details in Tables 2 and 3). TT ${ }^{1}$ Thickness and Threepoint bending; $\mathrm{M}^{2}$ Micro-indentation; $\mathrm{S}^{3}$ Scanning Electron Microscopy with Electron Back Scatter Diffraction (SEM-EBSD).

\begin{tabular}{lcccccccccc}
\hline Species & Sample ID & E1 & E2 & E3 & T1 & T2 & T3 & TT $^{\mathbf{1}}$ & $\mathbf{M}^{\mathbf{2}}$ & $\mathbf{S}^{\mathbf{3}}$ \\
\hline M. edulis & 72 & GG & TT & AA & AA & TT & CC & - & Yes & Yes \\
M. edulis & 75 & GG & TT & AA & AA & TT & CC & - & Yes & - \\
M. edulis & 77 & GG & TT & AA & AA & TT & CC & Yes & - & - \\
M. edulis & 78 & GG & TT & AA & AA & TT & CC & Yes & - & - \\
M. edulis & 81 & GG & TT & AA & AA & TT & CC & - & Yes & Yes \\
M. edulis & 87 & GG & TT & AA & AA & TT & CC & - & Yes & - \\
M. edulis & 91 & GG & TT & AA & AA & TT & CC & Yes & - & - \\
M. edulis & 95 & GG & TT & AA & AA & TT & CC & - & Yes & - \\
M. edulis & 96 & GG & TT & AA & AA & TT & CC & Yes & - & - \\
M. edulis & 107 & GG & TT & AA & AA & TT & CC & Yes & Yes & - \\
M. edulis & 108 & GG & TT & AA & AA & TT & CC & Yes & - & - \\
M. edulis & 109 & GG & TT & AA & AA & TT & CC & Yes & - & - \\
M. edulis & 122 & GG & TT & AA & AA & TT & CC & - & Yes & - \\
M. edulis & 123 & GG & TT & AA & AA & TT & CC & Yes & - & - \\
M. edulis & 126 & GG & TT & AA & AA & TT & CC & - & Yes & - \\
\hline
\end{tabular}


Table 1. Cont.

\begin{tabular}{|c|c|c|c|c|c|c|c|c|c|c|}
\hline Species & Sample ID & E1 & E2 & E3 & T1 & $\mathrm{T} 2$ & T3 & $\mathrm{TT}^{\mathbf{1}}$ & $\mathbf{M}^{2}$ & $S^{3}$ \\
\hline M. edulis & 128 & GG & TT & AA & AA & TT & $\mathrm{CC}$ & Yes & - & - \\
\hline M. edulis & 129 & GG & $\mathrm{TT}$ & $\mathrm{AA}$ & $\mathrm{AA}$ & $\mathrm{TT}$ & $\mathrm{CC}$ & Yes & - & - \\
\hline M. edulis & 132 & GG & TT & $\mathrm{AA}$ & AA & $\mathrm{TT}$ & $\mathrm{CC}$ & Yes & - & - \\
\hline M. edulis & 138 & GG & TT & $\mathrm{AA}$ & $\mathrm{AA}$ & $\mathrm{TT}$ & $\mathrm{CC}$ & Yes & - & - \\
\hline M. edulis & 144 & GG & $\mathrm{TT}$ & $\mathrm{AA}$ & $\mathrm{AA}$ & $\mathrm{TT}$ & $\mathrm{CC}$ & - & Yes & - \\
\hline M. edulis & 153 & GG & TT & AA & $\mathrm{AA}$ & $\mathrm{TT}$ & $\mathrm{CC}$ & Yes & - & - \\
\hline M. edulis & 154 & GG & TT & $\mathrm{AA}$ & $\mathrm{AA}$ & $\mathrm{TT}$ & $\mathrm{CC}$ & - & Yes & Yes \\
\hline M. edulis & 159 & GG & $\mathrm{TT}$ & $\mathrm{AA}$ & $\mathrm{AA}$ & TT & $\mathrm{CC}$ & Yes & - & - \\
\hline M. edulis & 161 & GG & $\mathrm{TT}$ & $\mathrm{AA}$ & $\mathrm{AA}$ & $\mathrm{TT}$ & $\mathrm{CC}$ & Yes & - & - \\
\hline M. edulis & 166 & GG & TT & $\mathrm{AA}$ & $\mathrm{AA}$ & TT & $\mathrm{CC}$ & Yes & - & - \\
\hline M. edulis & 172 & GG & TT & AA & AA & TT & $\mathrm{CC}$ & Yes & - & - \\
\hline M. edulis & 178 & GG & TT & $\mathrm{AA}$ & AA & TT & $\mathrm{CC}$ & Yes & - & - \\
\hline M. edulis & 183 & GG & $\mathrm{TT}$ & AA & AA & $\mathrm{TT}$ & $\mathrm{CC}$ & - & Yes & - \\
\hline F1 & 83 & AG & GT & AT & AG & GT & $\mathrm{CT}$ & Yes & Yes & Yes \\
\hline $\mathrm{F} 1$ & 168 & AG & GT & AT & AG & GT & $\mathrm{CT}$ & Yes & - & Yes \\
\hline $\mathrm{F} 1$ & 14 & AG & GT & AT & AG & GT & $\mathrm{CT}$ & - & Yes & Yes \\
\hline M. trossulus & 1 & $\mathrm{AA}$ & GG & AT & GG & GG & TT & - & Yes & - \\
\hline M. trossulus & 3 & $\mathrm{AA}$ & GG & $\mathrm{TT}$ & GG & GG & $\mathrm{TT}$ & - & Yes & - \\
\hline M. trossulus & 6 & $\mathrm{AA}$ & GG & $\mathrm{TT}$ & GG & GG & $\mathrm{TT}$ & - & Yes & - \\
\hline M. trossulus & 8 & $\mathrm{AA}$ & GG & $\mathrm{TT}$ & GG & GG & $\mathrm{TT}$ & - & Yes & - \\
\hline M. trossulus & 44 & AA & GG & TT & GG & GG & $\mathrm{TT}$ & - & Yes & - \\
\hline M. trossulus & 82 & $\mathrm{AA}$ & GG & TT & GG & GG & $\mathrm{TT}$ & Yes & Yes & Yes \\
\hline M. trossulus & 112 & AG & GG & AT & GG & GG & TT & Yes & Yes & Yes \\
\hline M. trossulus & 125 & AA & GG & $\mathrm{TT}$ & GG & GG & $\mathrm{TT}$ & - & - & Yes \\
\hline
\end{tabular}

Table 2. Individual mussels tested for Vickers hardness and fracture toughness (mean \pm SD).

\begin{tabular}{lccc}
\hline Species & Sample ID & $\begin{array}{c}\text { Vickers } \\
\text { Hardness (MPa) }\end{array}$ & $\begin{array}{c}\text { Fracture } \\
\text { Toughness/K }\end{array}$ IC (MPa) \\
\hline M. edulis & 72 & $214.90 \pm 21.37$ & $27.79 \pm 17.28$ \\
M. edulis & 75 & $165.45 \pm 25.48$ & $23.20 \pm 19.45$ \\
M. edulis & 81 & $215.83 \pm 13.08$ & $63.13 \pm 59.77$ \\
M. edulis & 87 & $192.20 \pm 26.38$ & $16.63 \pm 13.51$ \\
M. edulis & 95 & $206.59 \pm 11.31$ & $8.95 \pm 6.92$ \\
M. edulis & 107 & $154.65 \pm 37.12$ & $16.63 \pm 13.51$ \\
M. edulis & 122 & $202.31 \pm 5.48$ & $66.09 \pm 22.50$ \\
M. edulis & 126 & $199.04 \pm 21.41$ & $79.94 \pm 72.84$ \\
M. edulis & 144 & $199.04 \pm 21.41$ & $95.54 \pm 63.11$ \\
M. edulis & 154 & $199.93 \pm 6.48$ & $75.38 \pm 37.65$ \\
M. edulis & 183 & $186.92 \pm 16.56$ & $36.75 \pm 20.04$ \\
\hline F1 & 83 & $175.73 \pm 11.97$ & $92.36 \pm 63.61$ \\
F1 & 14 & $203.00 \pm 10.08$ & $38.37 \pm 39.70$ \\
\hline M. trossulus & 1 & $206.38 \pm 18.47$ & $28.00 \pm 20.85$ \\
M. trossulus & 3 & $208.62 \pm 8.11$ & $55.40 \pm 36.03$ \\
M. trossulus & 6 & $234.98 \pm 17.22$ & $62.22 \pm 29.48$ \\
M. trossulus & 8 & $190.40 \pm 13.28$ & $26.39 \pm 19.73$ \\
M. trossulus & 44 & $203.11 \pm 16.46$ & $86.64 \pm 70.53$ \\
M. trossulus & 82 & $190.66 \pm 13.97$ & $54.73 \pm 25.57$ \\
\hline
\end{tabular}


Table 3. Individual mussels tested for flexural strength, elasticity and shell thickness (mean \pm SD).

\begin{tabular}{|c|c|c|c|c|}
\hline Species & Sample ID & $\begin{array}{c}\text { Flexural } \\
\text { Strength (MPa) }\end{array}$ & Elasticity (MPa) & Thickness (mm) \\
\hline M. edulis & 77 & $31.28 \pm 3.97$ & $13.39 \pm 3.85$ & $1.22 \pm 0.08$ \\
\hline M. edulis & 78 & $36.05 \pm 6.31$ & $26.61 \pm 9.36$ & $1.18 \pm 020$ \\
\hline M. edulis & 91 & $47.66 \pm 7.43$ & $27.86 \pm 10.85$ & $1.30 \pm 0.12$ \\
\hline M. edulis & 96 & $56.43 \pm 2.14$ & $22.88 \pm 8.77$ & $0.78 \pm 0.02$ \\
\hline M. edulis & 107 & $48.36 \pm 14.44$ & $19.97 \pm 5.07$ & $1.17 \pm 0.18$ \\
\hline M. edulis & 108 & $66.11 \pm 18.83$ & $33.04 \pm 6.06$ & $1.01 \pm 0.14$ \\
\hline M. edulis & 109 & $64.54 \pm 19.33$ & $39.69 \pm 8.28$ & $0.98 \pm 0.05$ \\
\hline M. edulis & 123 & $33.98 \pm 4.73$ & $21.40 \pm 5.70$ & $0.83 \pm 0.14$ \\
\hline M. edulis & 128 & $19.32 \pm 4.47$ & $14.31 \pm 0.81$ & $1.18 \pm 0.14$ \\
\hline M. edulis & 129 & $35.81 \pm 10.59$ & $22.02 \pm 6.09$ & $1.33 \pm 0.30$ \\
\hline M. edulis & 132 & $60.31 \pm 6.86$ & $21.54 \pm 5.38$ & $0.89 \pm 0.12$ \\
\hline M. edulis & 138 & $52.67 \pm 17.05$ & $30.89 \pm 10.29$ & $1.05 \pm 0.32$ \\
\hline M. edulis & 153 & $27.25 \pm 7.31$ & $11.23 \pm 1.24$ & $1.24 \pm 0.23$ \\
\hline M. edulis & 159 & $55.47 \pm 17.27$ & $22.65 \pm 3.60$ & $1.09 \pm 0.07$ \\
\hline M. edulis & 161 & $38.12 \pm 10.28$ & $19.80 \pm 0.56$ & $1.06 \pm 0.06$ \\
\hline M. edulis & 166 & $65.47 \pm 17.02$ & $31.82 \pm 5.67$ & $0.92 \pm 0.04$ \\
\hline M. edulis & 172 & $40.99 \pm 11.79$ & $29.84 \pm 6.80$ & $1.36 \pm 0.29$ \\
\hline M. edulis & 178 & $29.42 \pm 6.94$ & $13.19 \pm 4.59$ & $1.11 \pm 0.26$ \\
\hline $\mathrm{F} 1$ & 83 & $31.90 \pm 8.55$ & $25.71 \pm 14.39$ & $1.09 \pm 0.20$ \\
\hline $\mathrm{F} 1$ & 168 & $91.13 \pm 38.45$ & $32.67 \pm 7.54$ & $0.97 \pm 0.15$ \\
\hline M. trossulus & 82 & $42.83 \pm 8.92$ & $16.88 \pm 4.55$ & $0.80 \pm 0.06$ \\
\hline M. trossulus & 112 & $31.86 \pm 10.17$ & $21.38 \pm 4.46$ & $1.22 \pm 0.17$ \\
\hline M. trossulus & 125 & $52.76 \pm 26.18$ & $27.21 \pm 12.42$ & $1.01 \pm 0.33$ \\
\hline
\end{tabular}

\subsection{Shell Thickness and Material Properties}

Mussel shells were cut into strips lengthways using a circular saw (Dremel). Three strips were cut from the hinge to the centre of the right valve and analysed blind (the analyst was not aware of the corresponding genotype). The width and depth for each strip was measured with an electronic calliper (RS Pro $150 \mathrm{~mm}$ digital calliper). The strips were loaded onto a Zwick/Roell 22.0 universal testing machine to perform the three-point bending test to determine the material properties of shell flexural strength and Young's elastic modulus. This had a standardised $35 \mathrm{~mm}$ gap between points, a $2.5 \mathrm{kN}$ load cell and a loading rate of $0.2 \mathrm{~mm}$ per minute was used. Each strip was placed with the outside convex curvature of the shell facing upwards, hinge left side and with the curved ends of the strip out with the $35 \mathrm{~mm}$ gap to minimise the effect of shell curvature on the breaking force. This measured the force $(\mathrm{N})$ and displacement $(\mathrm{mm})$ needed to break each strip. The flexural strength (in megapascals, $\mathrm{MPa}$ ) of each strip was calculated using the equation [15]:

$$
\text { Flexural strength }(\sigma)=\frac{3 F L}{2 b d^{2}}
$$

where $F$ is the force applied $(\mathrm{N}), L$ is the length of the span supporting the sample (standardised to $35 \mathrm{~mm}), b$ is the width of the sample and $d$ is the depth of the strip. Young's modulus (in $\mathrm{MPa}$ ) was calculated using the following equation:

$$
\text { Young's Modulus }(E)=\frac{L^{3} m}{4 b d^{3}}
$$

where $L, b$ and $d$ are as described above, and $m$ is the gradient of the straight line in the load deflection curve (plot of force versus deflection). The mean value from the three strips was used to describe the flexural strength of each individual tested. Measurements of shell thickness of each individual were taken in the middle of each strip using electronic callipers. 


\subsection{Aragonite and Calcite Crystallographic Orientation}

Calcite and aragonite crystallographic orientation was examined using Scanning Electron Microscopy with Electron Back Scatter Diffraction (SEM-EBSD) with a beam voltage of $20 \mathrm{kV}$ under low vacuum mode (50 Pa) on the FEI Quanta 200F Environmental SEM with the stage tilted to $70^{\circ} \mathrm{C}$ to examine backscatter kikuchi patterns [16] in three individuals of each identified genotype (pure M. edulis, pure M. trossulus and F1 hybrids), prepared as for micro-indentation. Crystallographic orientation was imaged across the middle section of the length of the mussel shell, examining the calcite/aragonite interface. Crystallographic orientation maps were produced through OIM Analysis v7.0 software. SEM-EBSD results are presented as crystallographic pole figures and orientation maps with each colour representing a particular crystallographic orientation (confidence index $\leq 0.1$ removed).

\subsection{Statistics}

Statistical analyses were performed on Minitab v17 statistical software. When necessary, data were log transformed to improve normality. One-way ANOVA with a Tukey comparison was used to test for significant differences of the measured phenotypes (shell thickness, flexural strength, Young's modulus, Vicker's hardness and fracture toughness) between the identified genotypes.

\section{Results}

\subsection{Genotyping}

The genotyped individuals were identified as $63.3 \%$ pure M. edulis, $16.7 \%$ introgressed $M$. edulis $/ M$. trossulus with various levels of heterozygosity, $15 \%$ pure M. trossulus and 5\% M. edulis/M. trossulus F1 hybrids. The SNP markers used here have been previously validated against Me15/16 for the same population in our previous work [3]. To compare meaningful shell characteristics between genotypes, we only report the individuals identified as pure M. edulis, F1 hybrids and pure M. trossulus (Table 1), therefore excluding mixed ancestries, which would instead constitute a confounding factor. In contrast with previous reports for Scottish waters, which have used both the same and different markers [3,7], no alleles of M. galloprovincialis were identified in the analysed sample population (data not shown).

\subsection{Phenotyping}

None of the measured parameters used here to describe the shell characteristics (Vicker's hardness, fracture toughness, flexural strength, shell thickness, elasticity, and aragonite/calcite crystal orientation), in the analysed sympatric population, have shown a statistically significant difference between the three identified genotypes (Figure 1).

The micro-indentation tests, which measure fracture toughness and Vickers hardness, showed the smallest variance compared to the three-point bending results (flexural strength and elasticity), as shown in Figure 1 and Table 2, with no statistically significant difference between the identified genotypes (hardness $p=0.75$, fracture toughness $p=0.10, M$. edulis $\mathrm{N}=11$, M. edulis / $M$. trossulus $\mathrm{F} 1$ hybrids $\mathrm{N}=2$ and $M$. trossulus $\mathrm{N}=6$ ).

These data are further supported by three-point bending tests for flexural strength and elasticity. We performed this test as this is the most comparable to the whole shell crushing tests. The results were highly variable between mussel shell strips (three per individual), further highlighting the need to exclude the shell shape heterogeneity from the whole shell crushing tests. To reduce variability in the data, only the mussels which showed the least variation (smaller than $33 \%$ of the mean) across the three shell strips were selected for statistical analysis, leaving 23 mussels $(\mathrm{N}=18$ M. edulis samples, $\mathrm{N}=3 \mathrm{M}$. trossulus samples, $\mathrm{N}=2 \mathrm{M}$. edulis / $M$. trossulus F1 hybrids; Table 3). Once again, out of the three phenotypes measured here (flexural strength, elasticity, and shell thickness), statistical analysis showed no significant differences between the three genotypes (Figure 1 and Table 3). The flexural strength measurements displayed a very large variation between individuals within the M. edulis and M. trossulus genotypes with no significant difference 
being observed between the three genotypes (Flexural strength $p=0.28$ ). In all cases, the homozygous $M$. trossulus and M. edulis / M. trossulus F1 hybrids were not statistically different from homozygous $M$. edulis samples. There was no significant difference for elasticity phenotype between the three genotypes $(p=0.27)$. The shell thickness phenotype was also not significantly different between homozygous $M$. trossulus, $M$. edulis / $M$. trossulus F1 hybrids and homozygous M. edulis $(p=0.50)$.
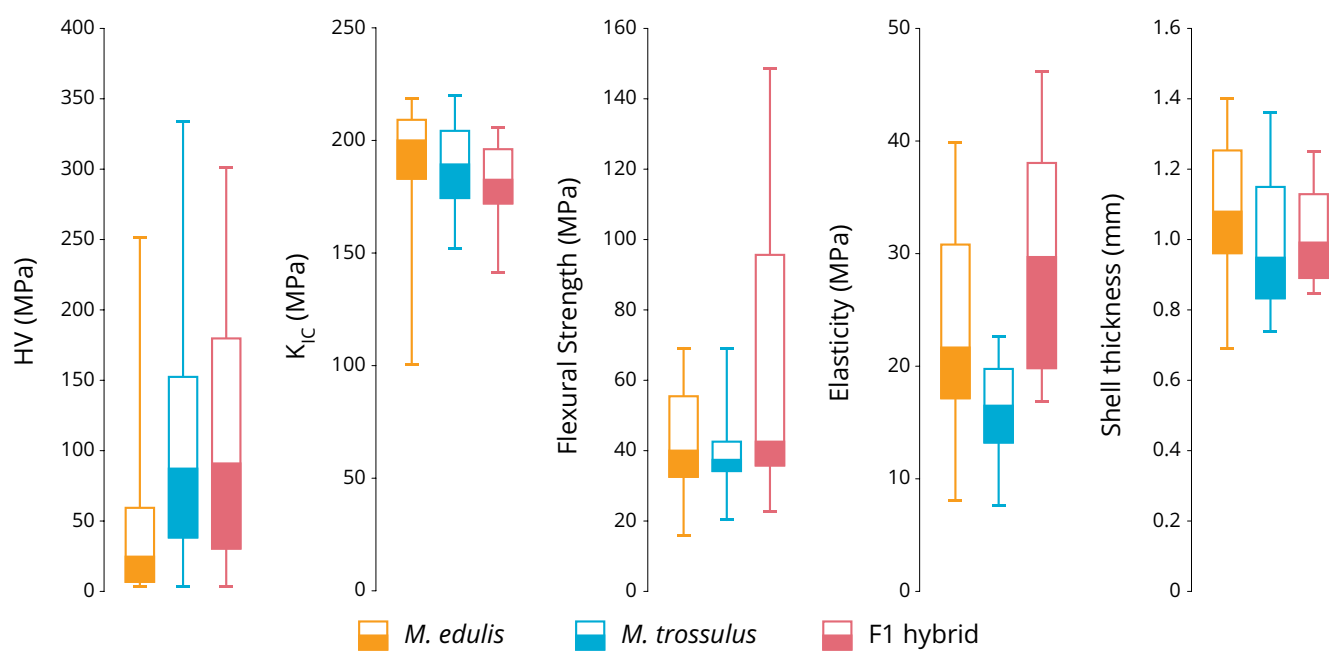

Figure 1. Boxplots comparing the phenotypes flexural strength, shell thickness, elasticity, hardness and fracture toughness to identified genotypes. The Boxplots show Q2, median and Q3 of samples and the whiskers indicate maximum and minimum values of each repeat for each sample. No statistically significant differences were identified between the genotypes by micro-indentation $(\mathrm{VH}$, Hardness $p=0.75 ; \mathrm{K}_{I C}$, fracture toughness $p=0.10 ;$ M. edulis $\mathrm{N}=11, \mathrm{~F} 1$ hybrids $\mathrm{N}=2$ and $M$. trossulus $\mathrm{N}=6$; see Table 2) or three-point bending tests (Flexural strength $p=0.2$, elasticity $p=0.27$, shell thickness $p=0.50$; M. edulis $\mathrm{N}=18, \mathrm{~F} 1$ hybrids $\mathrm{N}=2$ and $M$. trossulus $\mathrm{N}=3$; see Table 3).

These strength test results are further underpinned by the employment of Scanning Electron Microscopy with Electron Back Scatter Diffraction (SEM-EBSD), which assesses shell crystallographic orientation and provides structural justification for differences/similarities in shell strength results $[13,16]$. The microstructure of $M$. edulis is well known and has been described previously [13,16-18]. In Figure 2, the calcite prismatic layer appears from the outermost part of the shell at the top of the crystallographic orientation maps, to the calcite-aragonite interface, followed by the aragonite tablets, with the innermost part of the shell at the bottom of the map (Figure 2A-C). The calcite prisms and aragonite tablets are uniformly layered, as seen in the crystallographic orientation maps overlaid on the image quality of the SEM crystal structure (Figure 2C). The inverse pole figures (Figure 2D) demonstrate the spread of the crystallographic orientation data and highlight the co-orientation of the calcite fibres, clustering in the same angle of orientation on the c-axis as expected [18] for M. edulis and similarly between individuals of $M$. trossulus (Figure 2D). The SEM-EBSD data therefore suggest no difference in the shells' crystallographic structure between the three genotypes. 
A

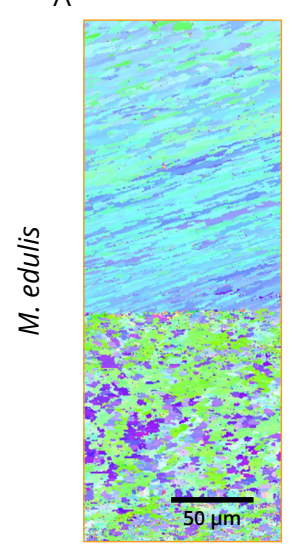

B
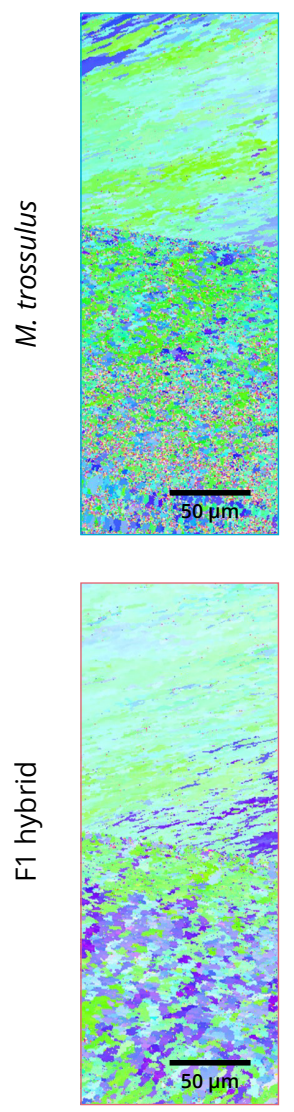
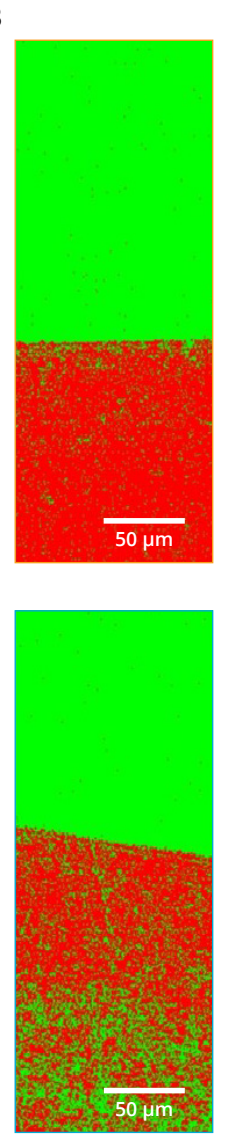

C
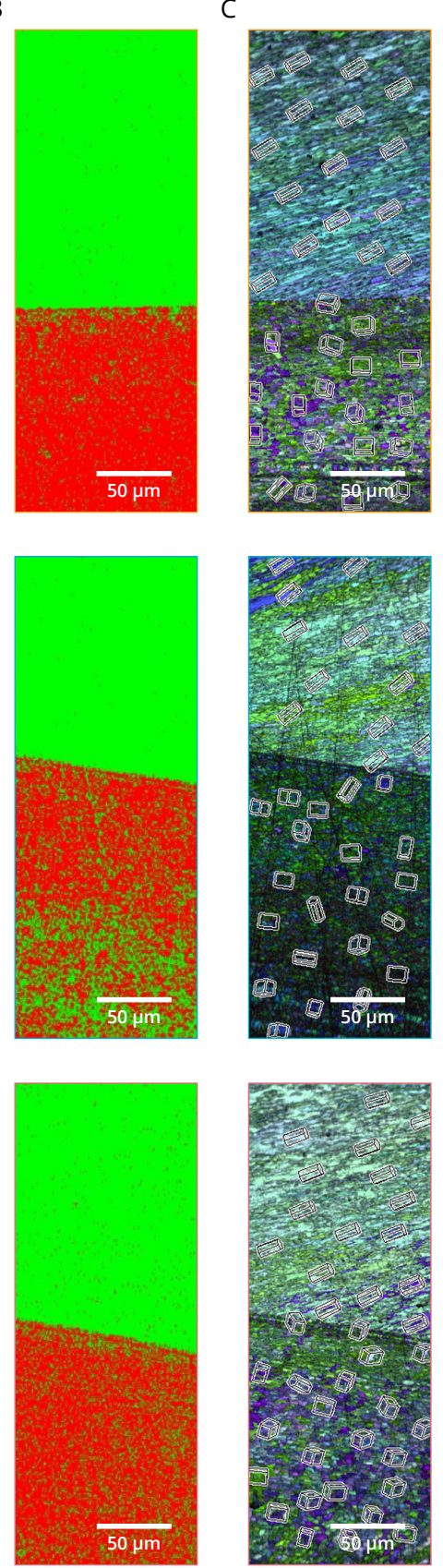

D
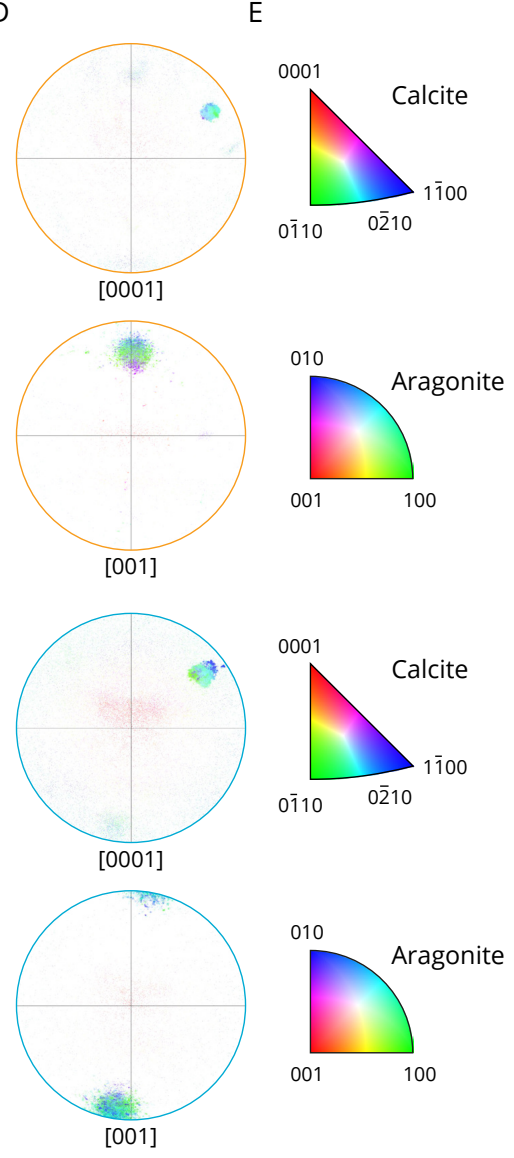

$0 \overline{1} 10$
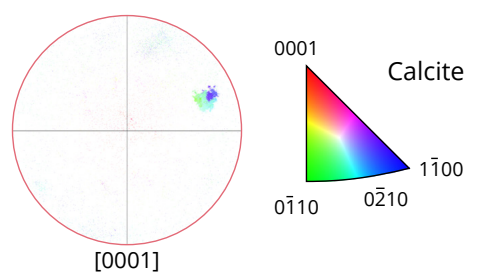

010

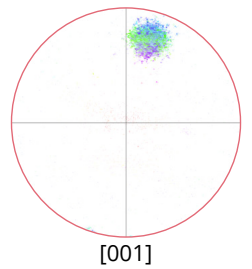

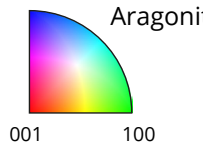

Figure 2. Typical examples (samples 72, 1 and 83 respectively) of scanning electron microscopy electron back-scatter diffraction (SEM-EBSD) data for one individual mussel of M. trossulus, M. edulis and F1 hybrid. (A) Crystallographic orientation maps for each species according to the colour keys (E) for calcite [0001] and aragonite [001]. (B) Crystallographic phase maps, the crystallographic phase maps have been colour coded with aragonite in red and calcite in green. (C) Crystallographic orientation map overlaid on the image quality of the SEM crystal structure with crystal lattices indicating the direction of the orientation of the crystal highlighted. (D) Inverse pole figures showing the crystallographic orientation data as per images (A).

\section{Discussion}

The whole shell-crushing tests often applied to commercial mussels are performed using an electronic force gauge screwed onto the shell at the widest part of the shell until it cracks [4]. Although very practical and inexpensive, allowing for high throughput, results of this test can be influenced by the variability in mussel shell shape [12]. Here we apply a 
combination of shell strength tests which are independent of the mussel heterogeneous shell shape and geometry, highlighting instead similarities in the crystal structure (Figure 2) and the resultant similarities in material properties indicative of shell strength (Figure 1) between genotypes. This method highlighted no differences in the shells crystallographic structure between the three genotypes further supporting the strength tests results.

Despite the limitations of this small study, its findings suggest that the current belief of a direct correlation between genotype and shell strength phenotype, where M. trossulus equals weaker shells, may not be as straightforward as previously thought (Table 3). Interestingly, the highest flexural strength was recorded in one M. edulis/M. trossulus F1 hybrid shell $(91.13 \pm 38.45 \mathrm{MPa})$ and the lowest one in an M. edulis shell $(19.32 \pm 4.47 \mathrm{MPa})$. This raises new questions around the theory that $M$. trossulus, as a species, has weaker shells compared to M. edulis. It is important to note that, in this study, genotypes have been assigned by a more robust multi-locus genotyping method, which inevitably narrowed down the opportunity to identify, or misidentify, a larger number of pure M. trossulus and F1 hybrids. The genotyped individuals revealed only $15 \%$ pure $M$. trossulus and $5 \%$ M. edulis / M. trossulus F1 hybrids, comparable to the higher estimated hybridisation levels of other shell strength studies using less robust genotyping methods [5] and confirms previous benchmarking of the employed SNPs against Me15/16 [3]. An overestimation of hybrid numbers could potentially hide individual variability within $M$. edulis or M. trossulus rather than the previously suggested significantly weaker shells of $M$. trossulus $[4,5]$. The use of multi-locus genotyping techniques, combined with state-of-the-art methodologies for material properties investigation in a sympatric population exposed to stable environmental conditions, indicates that genotype alone may not be responsible for the presence and abundance of weaker shells at commercial farm sites.

Coastal environmental parameters, such as temperature, salinity, $\mathrm{pH}$ and dissolved inorganic carbon, are in fact also likely to influence shell characteristics. These are often amplified in coastal areas, where mussel farming takes place, by climate change through temperature rises, $\mathrm{CO}_{2}$ induced ocean acidification and increased frequency of meteorological events causing high rainfall run-off [19]. It has been suggested that the variability of mussel shell shape is indeed directly influenced by environmental gradients; in particular, salinity was observed to be influential on shell shape, producing elongated and narrower shells in Mytilus sp. in different latitudinal regions [12]. Climate change driven $\mathrm{CO}_{2}$ induced ocean acidification has been well documented to cause changes to shell growth and the resultant shell strength phenotypes including reduced shell thickness and mechanically weaker shells in mussels [13,20], and oysters [21,22], often as a result of a reduced ability to biomineralise [23]. Here, we have focussed on one sympatric population of mussels, where historical temperature and salinity records at the study site for the past 10 years have shown a relatively homogenous marine environment with an average annual temperature of $9.5 \pm 2.6^{\circ} \mathrm{C}$ and average salinity of $31.7 \pm 1.6 \mathrm{ppt}$ [24]. In this study, the potential influence of highly variable environmental parameters on the mussel shell strength is therefore minimised. Even within a relatively stable coastal environment and by employing methods which minimise confounding factors, the variability in shell traits observed in this study is very high; this may contribute to the absence of statistical differences observed here.

Although further studies are required to validate the observations reported here, the data suggest that the influence of complex interactions between genotype and environment could be more linked to the presence and prevalence of weaker shells than genotype alone. Longline cultivated mussels show a weak correlation with species introgression and shell strength, but stronger effects of the environment such as depth and salinity on shell strength [25]. Commercial mussel productivity is reported to be limited by the occurrence of $M$. trossulus and its hybrids in certain areas [3,5,9]. Based on the data presented in this study and that by Michalek et al. [25], we suggest that the evidence linking negative shell phenotypic traits with genotype within the European Mytilus Species Complex may be weaker than previously thought. Under the conditions of this study, different genotypes of the complex present similar phenotypic shell traits. Further research is required to un- 
derstand the specific interactions between all key environmental parameters (temperature, salinity, $\mathrm{pH}$ and food availability) and phenotypic traits in all species of the complex. This would open up the possibility to investigate specific genotypes linked to shell strength at the individual/family level and therefore significantly beyond the mere observation of species classification.

Furthermore, to apply the tools described here to investigate the very practical problem of shell weakness in mussel farming, the set of phenotypes that better describes the shell weakness observed during harvesting still needs to be identified. The identification of a clear phenotype (flexural strength/elasticity/shell thickness/hardness or fracture toughness) directly linked to the observation of shell breakage during harvest will open up the possibility for genome wide association studies to identify the genes controlling for this significant commercial trait.

\section{Conclusions}

The hybridisation of the common blue mussel, M. edulis with M. trossulus, has been reported to produce mussels with weaker shells $[4,5]$ more vulnerable to damage by predation and prone to fracture during commercial grading and harvesting. The findings of this study, and others [25], call into question the validity of the hypothesised strong link between species and shell fragility. Despite the limitations of this small-scale study (limited sample size) and the large variance observed in many of the phenotypes, we found no correlation between shell strength and species alone. Further study is required to identify the true cause of shell weakness, including the consideration of environmental data (temperature, salinity, pressure, water current), biomineralisation mechanisms, and gene allele frequency.

Author Contributions: S.C. conceived the presented idea; S.C. and S.C.F. wrote the main manuscript; S.E. sampled the individuals and conducted flexural strength, elasticity testing and genotyping and wrote the first draft as part of her MSc degree. S.C.F. and K.E.T. designed material properties analyses, S.C.F. conducted hardness, fracture toughness testing and performed SEM analysis; M.B. and A.D. contributed to the data analysis and reviewed and finalised the manuscript. All authors have read and agreed to the published version of the manuscript.

Funding: S.E. was supported by the Scottish Aquaculture Innovation Centre (SAIC) and currently works for the Scottish shellfish marketing group. S.C.F. was supported by a NERC Independent Research Fellowship [NE/N01409X/1, NE/N01409X/2]. For the purpose of open access, the author has applied a CC BY public copyright licence to any Author Accepted Manuscript version arising from this submission.

Institutional Review Board Statement: This work was approved by the University of Stirling Ethics Committee (Animal Welfare and Ethics Review Board). Animal handling and collection in this study were carried out following its approved guidelines and regulations.

Informed Consent Statement: Not applicable.

Data Availability Statement: All data for Figure 1 are available in Tables 2 and 3.

Acknowledgments: All Authors wish to thank Iain MacKay and David Attwood of Loch Fyne Oysters Ltd for providing access to the biological material and the Scottish Environment Protection Agencies (SEPA) for providing the environmental data. All authors would like to thank Peter Chung, microanalyst at the Imaging Spectroscopy and Analysis Centre (ISAACs), University of Glasgow for support for the SEM analysis of the mussel shells.

Conflicts of Interest: The authors declare no conflict of interest.

\section{References}

1. Riginos, C.; Cunningham, C.W. Local adaptation and species segregation in two mussel (Mytilus edulis $\times$ Mytilus trossulus) hybrid zones. Mol. Ecol. 2005, 14, 381-400. [CrossRef] 
2. Gosling, E. Systematics and geographic distribution of Mytilus. In The Mussel Mytilus: Ecology, Physiology, Genetic and Culture; Number 25 in Developments in Aquaculture and Fisheries Science; Elsevier: Amsterdam, The Netherlands; New York, NY, USA, 1992.

3. Wilson, J.; Matejusova, I.; McIntosh, R.E.; Carboni, S.; Bekaert, M. New diagnostic SNP molecular markers for the Mytilus species complex. PLoS ONE 2018, 13, e0200654. [CrossRef] [PubMed]

4. Penney, R.W.; Hart, M.J.; Templeman, N.D. Shell strength and appearance in cultured blue mussels Mytilus edulis, M. trossulus, and M. edulis $\times$ M. trossulus hybrids. N. Am. J. Aquac. 2007, 69, 281-295. [CrossRef]

5. Beaumont, A.R.; Hawkins, M.P.; Doig, F.L.; Davies, I.M.; Snow, M. Three species of Mytilus and their hybrids identified in a scottish loch: Natives, relicts and invaders? J. Exp. Mar. Biol. Ecol. 2008, 367, 100-110. [CrossRef]

6. Dias, P.J.; Malgrange, B.; Snow, M.; Davies, I.M. Performance of mussels, Mytilus edulis, Mytilus trossulus, and their hybrids in cultivation at three scottish lochs. J. World Aquac. Soc. 2011, 42, 111-121. [CrossRef]

7. Michalek, K.; Ventura, A.; Sanders, T. Mytilus hybridisation and impact on aquaculture: A minireview. Mar. Genom. 2016, 27, 3-7. [CrossRef]

8. Wheelhouse, P. The aquaculture and fisheries (Scotland) act 2013 (specification of commercially damaging species) order 2014. Scott. Statut. Instrum. 2014, 176. Available online: https://www.legislation.gov.uk/ssi/2014/176/contents/made (accessed on 23 July 2021).

9. Dias, P.J.; Bland, M.; Shanks, A.M.; Beaumont, A.; Piertney, S.B.; Davies, I.M.; Snow, M. Mytilus species under rope culture in Scotland: Implications for management. Aquac. Int. 2009, 17, 437-448. [CrossRef]

10. Gosling, E.; Doherty, S.; Howley, N. Genetic characterization of hybrid mussel (Mytilus) populations on irish coasts. J. Mar. Biol. Assoc. U. K. 2008, 88, 341-346. [CrossRef]

11. Larrain, M.A.; Diaz, N.F.; Lamas, C.; Vargas, C.; Araneda, C. Genetic composition of Mytilus species in mussel populations from southern Chile. Fac. Am. J. Aquat. Res. 2012, 40, 1077-1084. [CrossRef]

12. Telesca, L.; Michalek, K.; Sanders, T.; Peck, L.S.; Thyrring, J.; Harper, E.M. Blue mussel shell shape plasticity and natural environments: A quantitative approach. Sci. Rep. 2018, 8, 2865. [CrossRef]

13. Fitzer, S.C.; Zhu, W.; Tanner, K.E.; Phoenix, V.R.; Kamenos, N.A.; Cusack, M. Ocean acidification alters the material properties of Mytilus edulis shells. J. R. Soc. Interface 2015, 12, 20141227. [CrossRef]

14. Lawn, B.R.; Evans, A.G.; Marshall, D.B. Elastic/plastic indentation damage in ceramics: The median/radial crack system. J. Am. Ceram Soc. 1980, 63, 574-581. [CrossRef]

15. Kamal, B.; Russell, D.; Payne, A.; Constante, D.; Tanner, K.E.; Isaksson, H.; Mathavan, N.; Cobb, S.R. Biomechanical properties of bone in a mouse model of Rett syndrome. Bone 2015, 71, 106-114. [CrossRef] [PubMed]

16. Pérez-Huerta, A.; Cusack, M. Optimizing electron backscatter diffraction of carbonate biominerals-resin type and carbon coating. Microsc. Microanal. 2009, 15, 197-203. [CrossRef]

17. Fitzer, S.C.; Cusack, M.; Phoenix, V.R.; Kamenos, N.A. Ocean acidification reduces the crystallographic control in juvenile mussel shells. J. Struct. Biol. 2014, 188, 39-45. [CrossRef]

18. Griesshaber, E.; Schmahl, W.W.; Ubhi, H.S.; Huber, J.; Nindiyasari, F.; Maier, B.; Ziegler, A. Homoepitaxial meso- and microscale crystal co-orientation and organic matrix network structure in Mytilus edulis nacre and calcite. Acta Biomater. 2013, 9, $9492-9502$. [CrossRef] [PubMed]

19. Fitzer, S.C.; Torres Gabarda, S.; Daly, L.; Hughes, B.; Dove, M.; O’Connor, W.; Potts, J.; Scanes, P.; Byrne, M. Coastal acidification impacts on shell mineral structure of bivalve mollusks. Ecol. Evol. 2018, 8, 8973-8984. [CrossRef]

20. Gazeau, F.; Quiblier, C.; Jansen, J.M.; Gattuso, J.P.; Middelburg, J.J.; Heip, C.H.R. Impact of elevated $\mathrm{CO}_{2}$ on shellfish calcification. Geophys. Res. Lett. 2007, 34, L07603. [CrossRef]

21. Beniash, E.; Ivanina, A.; Lieb, N.; Kurochkin, I.; Sokolova, I. Elevated level of carbon dioxide affects metabolism and shell formation in oysters Crassostrea virginica. Mar. Ecol. Prog. Ser. 2010, 419, 95-108. [CrossRef]

22. Dickinson, G.H.; Ivanina, A.V.; Matoo, O.B.; Pörtner, H.O.; Lannig, G.; Bock, C.; Beniash, E.; Sokolova, I.M. Interactive effects of salinity and elevated $\mathrm{CO}_{2}$ levels on juvenile eastern oysters, Crassostrea virginica. J. Exp. Biol. 2012, 215, 29-43. [CrossRef] [PubMed]

23. Fitzer, S.C.; Phoenix, V.R.; Cusack, M.; Kamenos, N.A. Ocean acidification impacts mussel control on biomineralisation. Sci. Rep. 2015, 4, 6218. [CrossRef] [PubMed]

24. SEPA. Scottish Environment Protection Agency Database; SEPA: Stirling, UK, 2020.

25. Michalek, K.; Vendrami, D.L.; Bekaert, M.; Green, D.H.; Last, K.S.; Telesca, L.; Wilding, T.A.; Hoffman, J.I. Mytilus trossulus introgression and consequences for shell traits in longline cultivated mussels. Evol. Appl. 2021. [CrossRef] 